\title{
Temporal Changes in Lung Cancer: A 10-year Study in a Chest Hospital
}

\author{
H. Halilcolar, S. Yapicioglu, S. Bilaceroglu
}

ABSTRACT: Temporal Changes in Lung Cancer: A 10-year Study in a Chest Hospital. H. Halilcolar, S. Yapicioglu, S. Bilaceroglu.

Background and Aim. No prospective, wide-scale study on lung cancer (LC) exists in Turkey. We aimed to determine prospectively epidemiologic features, histologic types, stages and temporal changes in LC in the Aegean Region of Turkey. This is the first prospective and largest LC study in Turkey.

Methods. A hospital-based study was conducted on LC cases diagnosed between 1994 and 2004 at a tertiary referral hospital for thoracic medicine and surgery in Izmir, Turkey. The study was divided into two 5-year periods to determine temporal changes.

Results. Of 13,344 patients with pathologically confirmed LC, $93.1 \%$ was male. The mean age was $61.35 \pm 0.08(59.5 \%$ between $41-65)$. The majority $(82.5 \%)$ were smokers or ex-smokers. There was a $13.87 \%$ general rise in smoking rate, predominantly in females. $L C$ in- cidence increased by $38 \%$ from $1994-1999(42 \%)$ to 2000 $2004(58 \%)$; the contributive increases were $35.5 \%$ in males, and $77.5 \%$ in females. Frequent types were squamous cell carcinoma $(24.7 \%)$, small cell carcinoma (SCLC) $(14.2 \%)$ and adenocarcinoma (13.2\%). Adenocarcinoma in the younger group $(<40)$, females or nonsmokers, and squamous cell carcinoma in the older group, males or smokers were the leading types. Nonsmall cell lung carcinoma (NSCLC) was mostly diagnosed at stages IIIB $(36.7 \%)$ and IV $(37 \%)$ whereas SCLC at limited stage $(\mathbf{5 9 . 1 \%})$.

Conclusion. The majority of the LC patients are over 40 years old, current or ex-smokers, or with squamous cell carcinoma. There is a general rise in smoking rate with a female predominance. The most common type is squamous cell carcinoma in males, and adenocarcinoma in females. NSCLC is diagnosed more frequently at advanced stage but SCLC at limited stage.

Monaldi Arch Chest Dis 2008; 69: 4, 157-163.

Keywords: Cancer, Epidemiology, Lung, Pathology, Smoking.

Department of Thoracic Medicine, Izmir Training and Research Hospital for Thoracic Medicine and Surgery, Izmir, Turkey.

Correspondence: Semra Bilaceroglu, 6026 Sokak No: 197/22, 35560 Bostanli / Izmir Turkey; e-mail: semrab@superonline.com

\section{Introduction}

Currently, lung cancer (LC) has become the world's leading cause of cancer mortality in both genders $[1,2]$. Smoking, the most common cause of LC [2, 3], increases LC risk 20-fold [2]. With an increasing prevalence over the past three decades in Turkey, smoking rate is high in males $(63 \%)$ and lower but rapidly increasing in females (24\%) [4, 5]. Smoking habit and behaviour have altered the epidemiology, including histology, of LC in Turkey as in the other countries [2, 6-9].

Prospectively-obtained and wide-scale LC data have never been available in Turkey. Cancer registration systems by the Ministry of Health did not reflect the expected numbers [8]. In 1992, the first population-based cancer registration system [9] was established in Izmir, the third biggest city of Turkey with a cosmopolitan population of $3,370,866$. Owing to internal migrations, Izmir can be considered, to some extent, representative of Turkey's population. Our 450-bed hospital in Izmir, being specialized in thoracic medicine and surgery, receives patients from the whole Aegean region (a 85,000 -sq $\mathrm{km}$ area and 8,938,780-people population and $13 \%$ of Turkey's population). In this hospi- tal-based study, we aimed to determine the epidemiologic characteristics, histologic types, stages, and temporal changes of LC in the Aegean Region by observing LC prospectively in a fairly representative population over a 10 -year period. This is the first prospective and largest LC study in Turkey.

\section{Methods}

\section{Subjects}

All patients diagnosed with primary LC between 1994 and 2004 in Izmir Training and Research Hospital for Thoracic Medicine and Surgery (ITRHTMS) were included in the study. Cases suggesting LC but with no pathological evidence, and those with pleural mesothelioma or metastatic pulmonary and pleural malignancies from other primary sites were excluded.

The study was approved by the institutional review board. The patients were informed about the study and confidentiality of the results.

\section{Data Collection and Study Design}

In this prospectively conducted study; demographic and epidemiologic data, smoking status, 
histological types and stages of LC cases were collected and recorded electronically on specially prepared charts by the investigators in the Malignancy Study Group of ITRHTMS. Repetition in the registration of the patients were avoided by meticulous screening of the demographic data.

The study was divided into two periods (19941999 and 2000-2004) to compare the temporal changes in the number, age, gender, smoking status and histological types of the cases.

Histological classification was carried out according to the histological typing of lung tumours (1999) by World Health Organisation [10].

Non-smokers (NS) were defined as patients who had smoked fewer than 100 cigarettes during lifetime, current smokers (CS) as those who had been smoking at least one cigarette/day for at least one year prior to diagnosis, and ex-smokers (ES) as those having given up smoking for at least one year prior to diagnosis. The charts included no information about passive smoking.

\section{Statistics}

Unpaired $t$ test was performed for analysing temporal change in age, and chi-square test for other comparisons by using SPSS 11.0 program. A $p$ value of less than 0.05 was considered significant.

\section{Results}

There were a total of 13,935 cases considered to be LC from 1994 through 2004. Of these, 591 did not have pathologic proofs and thus, were excluded from the study.

\section{Demographic features in LC}

Of the remaining 13,344 with pathologically proven LC, $12,424(93.1 \%)$ were male, and 920 $(6.9 \%)$ female. The mean age was $61.35 \pm 0.08$ (2597 years). The median age was 62 . There was no significant difference between the mean ages of the genders. 417 patients $(3.1 \%)$ were under age 40, $7943(59.5 \%)$ between 41 and 65, and 4984 (37.4\%) over 65 . Incidence of LC in the same age group did not show significant difference between genders.

\section{Temporal changes in demographic features}

The total number of cases increased by $38 \%$ from [5606 (42\%)] in 1994-1999 to [7738 (58\%)] in 2000-2004. This increase was caused by the increases in both male $(35.5 \%)$ and female patients (77.5\%) (figure 1). The mean ages in 1994-1999 and 2000-2004 were $60.8 \pm 0.13$ and $61.7 \pm 0.11$, respectively. The mean age showed a significant temporal increase from $60.8 \pm 0.13$ to $61.1 \pm 0.12$ $(\mathrm{p}<0.001)$ in men whereas it was comparable $(61.0 \pm 0.65$ and $61.3 \pm 0.52)$ in women.

\section{Smoking status in LC}

CS constituted $73.9 \%$, ES $8.6 \%$, and NS $8.7 \%$ of the cases. In $8.8 \%$, there were no recorded data about smoking status. Male CS considerably exceeded the female CS $(p<0.001)$. CS in men and NS in women were predominant in all age groups. Incidence of smoking significantly increased in both genders. The increase in the general smoking rate (CS and ES) was $13.87 \%$ from $1994-1999$ (34.32\%) to 2000 2004 (48.19\%). The increase in women (10.6\%) was more noticeable $(p<0.001)$ with a change from $22.6 \%$ to $33.2 \%$. However, in men it was only a $1.8 \%$ rise from $85.4 \%$ to $87.2 \%$ (table 1 ).

\section{Histological features}

Of the 13,344 cases of LC, the leading cell types were unspecified non-small cell (NSCLC) $(34.43 \%)$, squamous cell $(24.7 \%)$, small cell (SCLC) $(14.2 \%)$ and adenocarcinoma (13.2\%). Squamous cell carcinoma $(25.9 \%)$ in males and adenocarcinoma in females $(32.8 \%)$ were the most common specified types. Squamous cell carcinoma constituted $46 \%$, SCLC $26.4 \%$, adenocarcinoma $24.6 \%$, and large cell carcinoma $1.5 \%$ of the 7,166 cases with specified type (excluding cases NSCLC or solely malignant pathology with unspecified subtype or type). Adenocarcinoma $(23.5 \%)$ was mostly seen under age 40 whereas squamous cell carcinoma between 41-65 (24.9\%) and over $65(25.3 \%)$.

In 1994-1999, the leading cell types in men were squamous cell $(28.9 \%)$, SCLC $(15 \%)$ and adenocarcinoma (10.2\%). In 2000-2004, this order did not change but adenocarcinoma frequency increased while squamous cell or SCLC frequency decreased. In women, adenocarcinoma (28.1\%), squamous cell carcinoma (10.3\%) and SCLC $(9.4 \%)$ were the leading types in 1994-1999. In 2000-2004, frequency order changed as adenocarcinoma, SCLC and squamous cell carcinoma. The increase in adenocarcinoma incidence in women was significant $(p=0.027)$ (table 2$)$.

Squamous cell carcinoma in CS and ES groups, and adenocarcinoma in NS group were the most common tumours in both periods. (Tables 3 and 4). NSCLC was mostly diagnosed at advanced

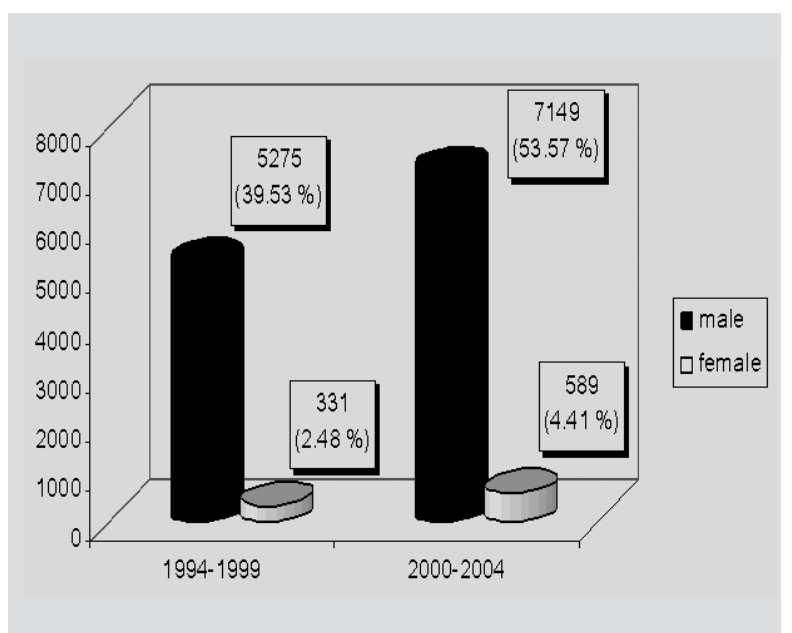

Fig. 1. - The incidence of lung cancer by gender in the two 5-year periods of the study 
Table 1. - Smoking status by gender during the two 5-year periods of the study

\begin{tabular}{|c|c|c|c|c|c|c|c|c|}
\hline & \multicolumn{4}{|c|}{ Female } & \multicolumn{4}{|c|}{ Male } \\
\hline & \multicolumn{2}{|c|}{ 1994-1999 } & \multicolumn{2}{|c|}{$2000-2004$} & \multicolumn{2}{|c|}{ 1994-1999 } & \multicolumn{2}{|c|}{$2000-2004$} \\
\hline & $n$ & $\%$ & $n$ & $\%$ & $n$ & $\%$ & $n$ & $\%$ \\
\hline CS * & 62 & 18.7 & 177 & 30.1 & 3885 & 73.6 & 5743 & 80.3 \\
\hline $\mathbf{N S}{ }^{\dagger}$ & 202 & 61.0 & 326 & 55.3 & 282 & 5.3 & 347 & 4.9 \\
\hline $\mathbf{E S} \doteqdot$ & 13 & 3.9 & 18 & 3.1 & 620 & 11.8 & 493 & 6.9 \\
\hline Unknown & 54 & 16.3 & 68 & 11.5 & 488 & 9.3 & 566 & 7.9 \\
\hline Total & 331 & & 589 & & 5275 & & 7149 & \\
\hline
\end{tabular}

* CS: Current smokers.

$\dagger$ NS: Non-smokers.

$\doteqdot$ ES: Ex-smokers.

Table 2. - Histological types of lung cancer by gender during the two periods of the study

\begin{tabular}{|c|c|c|c|c|c|c|c|c|}
\hline & \multicolumn{4}{|c|}{ Male } & \multicolumn{4}{|c|}{ Female } \\
\hline & \multicolumn{2}{|c|}{ 1994-1999 } & \multicolumn{2}{|c|}{ 2000-2004 } & \multicolumn{2}{|c|}{ 1994-1999 } & \multicolumn{2}{|c|}{ 2000-2004 } \\
\hline & $n$ & $\%$ & $n$ & $\%$ & $n$ & $\%$ & $n$ & $\%$ \\
\hline Squamous cell CA* & 1525 & 28.91 & 1698 & 23.75 & 34 & 10.27 & 45 & 7.64 \\
\hline Small cell CA* & 793 & 15.03 & 1013 & 14.17 & 31 & 9.37 & 57 & 9.68 \\
\hline AdenoCA* & 551 & 10.44 & 950 & 13.29 & 97 & 29.31 & 224 & 38.03 \\
\hline Large cell $\mathrm{CA}^{*}$ & 75 & 1.42 & 30 & 0.42 & 4 & 1.20 & 1 & 0.17 \\
\hline Adenosquamous CA* & 7 & 0.14 & 2 & 0.03 & 2 & 0.60 & 1 & 0.17 \\
\hline Unspecified NSCLC ${ }^{\dagger}$ & 1700 & 32.23 & 2625 & 36.72 & 107 & 32.33 & 162 & 27.50 \\
\hline Malignant/type $\varnothing \ddagger$ & 623 & 11.81 & 818 & 11.44 & 56 & 16.92 & 87 & 14.77 \\
\hline Carcinoid TM $\$$ & - & - & 11 & 0.15 & - & - & 12 & 2.04 \\
\hline Neuroendocrine TM $§$ & 1 & 0.02 & 2 & 0.03 & - & - & - & - \\
\hline Total & 5275 & & 7149 & & 331 & & 589 & \\
\hline
\end{tabular}

* CA: carcinoma; adenoCA.: adenocarcinoma.

$\dagger$ unspecified NSCLC: non-small cell carcinoma with undetermined subtype.

$\doteqdot$ malignant/type $\varnothing$ : malignancy determined but cell type unspecified.

\& TM: tumor.

Table 3. - Histological types by smoking status during the 1994-1999 period

\begin{tabular}{|c|c|c|c|c|c|c|}
\hline & \multicolumn{2}{|c|}{ Current smoker } & \multicolumn{2}{|c|}{ Non-smoker } & \multicolumn{2}{|c|}{ Ex-smoker } \\
\hline & $\mathbf{n}$ & $\%$ & $\mathbf{n}$ & $\%$ & $\mathbf{n}$ & $\%$ \\
\hline Squamous cell CA* & 1103 & 27.95 & 78 & 16.12 & 221 & 34.91 \\
\hline Small cell CA* & 600 & 15.20 & 48 & 9.92 & 90 & 14.22 \\
\hline AdenoCA* & 388 & 9.83 & 121 & 25.00 & 70 & 11.06 \\
\hline Large cell CA* & 53 & 1.34 & 8 & 1.65 & 11 & 1.74 \\
\hline Adenosquamous CA* & 4 & 0.10 & 2 & 0.41 & 3 & 0.47 \\
\hline Unspecified NSCLC ${ }^{\dagger}$ & 1341 & 33.98 & 154 & 31.82 & 167 & 26.38 \\
\hline Malignant/type Ø & 457 & 11.58 & 73 & 15.08 & 71 & 11.22 \\
\hline Carcinoid TM $\$$ & 0 & 0 & 0 & 0 & 0 & 0.0 \\
\hline Neuroendocrine TM $\$$ & 1 & 0.02 & 0 & 0 & 0 & 0.0 \\
\hline Total & 3947 & & 484 & & 633 & \\
\hline
\end{tabular}

* CA: carcinoma; adenoCA.: adenocarcinoma.

$\dagger$ unspecified NSCLC: non-small cell carcinoma with undetermined subtype.

$\doteqdot$ malignant/type $\varnothing$ : malignancy determined but cell type unspecified.

§ TM: tumor. 
Table 4. - Histological types by smoking status during the 2000-2004 period

\begin{tabular}{|c|c|c|c|c|c|c|}
\hline & \multicolumn{2}{|c|}{ Current smoker } & \multicolumn{2}{|c|}{ Non-smoker } & \multicolumn{2}{|c|}{ Ex-smoker } \\
\hline & $\mathbf{n}$ & $\%$ & $\mathbf{n}$ & $\%$ & $\mathbf{n}$ & $\%$ \\
\hline Squamous cell CA* & 1369 & 23.12 & 77 & 11.44 & 149 & 29.16 \\
\hline Small cell CA* & 878 & 14.83 & 53 & 7.87 & 48 & 9.39 \\
\hline AdenoCA* & 781 & 13.19 & 214 & 31.80 & 76 & 14.87 \\
\hline Large cell $\mathrm{CA}^{*}$ & 26 & 0.44 & 3 & 0.45 & 1 & 0.20 \\
\hline Adenosquamous CA* & 2 & 0.03 & 1 & 0.15 & 0 & 0 \\
\hline Unspecified NSCLC ${ }^{\dagger}$ & 2189 & 36.98 & 213 & 31.65 & 170 & 33.26 \\
\hline Malignant/type Ø & 667 & 11.27 & 99 & 14.71 & 64 & 12.52 \\
\hline Carcinoid TM§ & 7 & 0.12 & 13 & 1.93 & 2 & 0.40 \\
\hline Neuroendocrine TM§ & 1 & 0.02 & 0 & 0 & 1 & 0.20 \\
\hline Total & 5920 & & 673 & & 511 & \\
\hline
\end{tabular}

* CA: carcinoma; adenoCA.: adenocarcinoma.

$\dagger$ unspecified NSCLC: non-small cell carcinoma with undetermined subtype.

$\ddagger$ malignant/type $\varnothing$ : malignancy determined but cell type unspecified.

$\S$ TM: tumor.

Table 5. - Stage of lung cancer

\begin{tabular}{lcc}
\hline & $\mathbf{n}$ & $\%$ \\
\hline NSCLC & 1199 & 11.7 \\
$\boldsymbol{I}$ & 583 & 5.7 \\
II & 913 & 8.9 \\
IIIA & 3757 & 36.7 \\
IIIB & 3789 & 37 \\
IV & $10241^{*}$ & 100 \\
& & \\
SCLC & 969 & 59.1 \\
Limited disease & 733 & 40.9 \\
Extensive disease & $1702^{\dagger}$ & 100 \\
& 11943 & 100 \\
Total & & \\
\hline Total numbers of *NSCLC and ${ }^{*}$ SCLC patients staged.
\end{tabular}

stage (stage IIIB or IV) whereas SCLC mostly at limited-disease stage (Table 5).

\section{Discussion}

This study has shown that despite the fact that the majority of LC cases are male and that there is a temporal rising tendency of the incidence in both genders, the rise in females is more noticeable in the Aegean Region of Turkey. Moreover, it has revealed that the increase in smokers in both genders is alarming and can lead to an increased risk and incidence of LC.

This is not a population-based study; however according to the data of Izmir Cancer Registry, $60 \%$ of the patients with lung cancer in the Aegean Region has been diagnosed and treated in our hos- pital [9]. Furthermore, all of the LC patients in the current study were prospectively included and this study group totalled up to a high number. The prospective design and high number of patients (13344) makes the data of this study more reliable and accurate even though they reflect only one region. Prospectively obtained and wide-scale LC data have never been available in Turkey previously.

According to the data of Izmir Cancer Registry, LC is the most common cancer $(42.3 \%$ of all cancers) in males, and the annual age-standardised incidence rate is 61.6/100 000 in males and $5.1 / 100000$ in females for the years 1993-1994 [9]. LC is the leading cause of cancer deaths in both men and women in the developed world [11]. Furthermore, $17.8 \%$ of all cancer deaths and $12.8 \%$ of the general cancer incidence of the world are attributable to LC [1]. The global incidence of LC is increasing at a rate of $0.5 \%$ per year [12].

Epidemiologic changes in the incidence of LC can be directly attributed to the changing smoking rates throughout the world. These changes occur in both genders $[11,13]$. In the U.S., a decreasing trend in LC incidence started during 1980s in males and reached a rate of $2.3 \%$ per year between 1990-1995 [11]. The same trend has been observed in northern and western Europe. However, the incidence in males has been increasing in the eastern and southern parts of the continent [1]. In the current study, the $35.5 \%$ increase in males within the $38 \%$ general increase was consistent with those in eastern and southern Europe.

In the early 1900s, LC was exceptional in men and women. LC epidemic began after 1930 in men [11]. Women started smoking in significant numbers during and following World War II. The ageadjusted lung cancer death rates and smoking rates among women have risen in a parallel fashion. There was a 15 to 20-year latency period between 
initiation of smoking and death from lung cancer [14]. Starting from the 1960s lung cancer has progressively reached epidemic proportion, surpassing breast cancer in 1987 and becoming the leading cause of cancer deaths among women. Over the past 30 years, there has been a four-fold increase in LC in women, altering the male/female ratio of the disease. It is estimated that this rise will not plateau until after $2010[15,16]$. The $77.9 \%$ increase in women in our study was remarkable and exceeded two times that in males in the last five years of the study.

LC incidence increases with age. LC is rarely seen in young adults $[17,18]$. In UK's LC statistics, LC is rarely diagnosed in those under age 40 but the incidence rises rapidly thereafter, peaking in those aged 70-79 [19]. According to the 1994-1998 data by Turkish Thoracic Society, Lung and Pleural Malignancies Study Group, $56.7 \%$ of the cases in Turkey were within the age range 46-65 [20]. Similarly, in our study too, $59.5 \%$ of the cases were distributed between the ages 41 and 65 .

The incidence of LC is closely related to the prevalance of smoking, the most important known risk factor for LC [2]. Generally, prevalance of smoking is lower in females (10$12 \%)$ than that in males (47-52\%). In developed countries, the prevalance in females $(20-40 \%)$ approaches that in males $(30-40 \%)$ but in developing countries, it is somewhat lower (2-10\%) than that of males $(40-60 \%)[17,21]$. Cigarette consumption in Turkey increased by $10 \%$ from 1970 to 1985 and by $44 \%$ in 1988 , with $63 \%$ of males and $24 \%$ of females smoking [4]. In China, where a third of the world's smokers reside, the male smoking population is $67 \%$, almost equal to that in Turkey $[21,22]$. Cigarette consumption is predicted to continue rising in Turkey as determined in our study and others $[4,11]$. The increased proportion of smokers in both genders, especially in teenagers, is alarming $[4,13]$. The $82.4 \%$ smoking rate and the $13.87 \%$ rise in this rate in our study show the critical role of cigarette smoking in acquiring $\mathrm{LC}$.

In several western European countries, there has been a decrease in the overall incidence of LC consequent to the decrease in male smokers. Unfortunately, women have increasingly been taking up smoking, often at younger ages. In all countries, except UK, LC incidence in women is climbing $[16,22]$. In our study, smokers (CS and ES) increased and NS decreased significantly in both genders. However, the male CS considerably exceeded the female counterparts in number, and CS in men and NS in women were predominant in all age groups.

Histologic nature of LC has been changing with an increase in adenocarcinoma incidence compared with other types. This is probably multifactorial and requires further research to clarify the different influences. Diagnosis and classification of LC have changed with the new diagnostic techniques and changing features of cigarettes and smoking behaviours [2, 6, 7]. Smoking increases the risk of all histological types of LC although the risk is greater for squamous cell carcinoma and SCLC than for adenocarcinoma [23, 24, 25].

In the U.S., adenocarcinoma is currently the most frequent histological type of LC in both genders [26]. In France, squamous cell carcinoma still predominates but a recent increase in adenocarcinoma has been observed. Patients with adenocarcinoma have a trend towards more frequent deep inhalations and use of filter cigarettes. On the other hand, patients with squamous cell carcinoma more frequently smoke hand-rolled cigarettes [27]. In Denmark, the incidences of squamous cell carcinoma, SCLC and large cell carcinoma have decreased whereas that of adenocarcinoma has increased [28]. In contrast to the western world, in Asian countries such as Korea and China [29, 30], the leading type is squamous cell carcinoma. In our study, similar to those in other developing countries, squamous cell carcinoma was the most frequent LC, followed by SCLC and adenocarcinoma.

The high rate of unspecified NSCLC $(34.4 \%)$ in our study might be due to small or poorly preserved biopsy specimens and/or the very recent availability of immunohistochemical studies in our hospital. Our results are consistent with those in the study of the Turkish Thoracic Society, Lung and Pleural Malignancies Study Group [20]. We observed a lower frequency of large cell carcinoma $(1.5 \%)$ in our study than in other studies from different countries $(10 \%)$ [28, 31]. This low frequency might be partly explained by possible pooling of some large cell carcinoma cases within the unspecified NSCLC group.

Incidences of histological types of LC vary by gender. In the U.S., increasing adenocarcinoma and decreasing squamous cell carcinoma rates in men have been reported whereas all types have been increasing in women $[23,26]$. A similar trend beginning in the second half of 1980s has been observed in Europe [6, 23, 32]. In our study, squamous cell carcinoma was the leading type followed by SCLC and adenocarcinoma in males. However, the leading type in females was adenocarcinoma followed by SCLC and squamous cell carcinoma. Throughout the 10 -year study period, adenocarcinoma remained as the leading type in females as in the other countries. Women smokers are more likely to develop adenocarcinoma of the lung and estrogens may play a causative role in this phenomenon [14]. Squamous cell carcinoma has decreased, and adenocarcinoma increased in frequency in both genders with a considerable rise in females. SCLC has shown a decreasing trend in men but a stable course in women.

Adenocarcinoma under age 40 and squamous cell carcinoma over 40 were the most frequently encountered types in the current study. This result can be partly explained by smoking of predominantly unfiltered, high-tar products by patients over 40 and resulting deposition of carcinogens in central bronchi, where squamous cell carcinomas often develop [7, 33, 34].

Smoking increases the risk of all types of LC. In the US and in Europe, squamous cell car- 
cinoma is the most frequent type among smokers, and SCLC is the next frequent type. However, adenocarcinoma is the most frequent type in NS $[7,13,35]$. Our study also showed that in smokers (CS and ES), squamous cell carcinoma was the most frequent, followed by SCLC whereas in NS group, adenocarcinoma was the most frequent, followed by squamous cell carcinoma.

About two thirds of the patients do not have the chance for the radical surgical treatment since a high proportion of LCs is either locally advanced (Stage IIIA or IIIB) or metastatic disease (stage IV) at diagnosis [17]. In Turkey, this rate is even higher as has been demonstrated in the study of Turkish Thoracic Society Study Group (86.7\%) [20] and that our own (82.6\%). That NSCLC is diagnosed at more advanced stages in Turkey than in developed countries [17] may be partly because of socio-economical problems and lack of routine health checks. Two thirds of SCLC patients also have extensive disease at diagnosis [36]. This rate is close to that in the study of Turkish Thoracic Society Study Group (62.1\%) [20]. In contrast, limited-stage patients $(59.1 \%)$ exceeded the extensive-stage patients (40.9\%) in ours. Although we cannot definitively explain this finding, one reason may be the symptoms beginning earlier in SCLC due to its faster growth and tendency to develop more centrally. Since staging with abdominal ultrasound or CT, brain CT and bone scanning was performed according to the presence of organ-specific symptom(s), we might have missed asymptomatic metastases. Thus, such an approach might have led to pseudo dominance of limited stage.

In conclusion, although the majority of LC cases are male and there is a temporal rising tendency in incidence for both genders, the rise in females is more noticeable; most patients are over 40, CS or ES and with squamous cell carcinoma; the leading histological type is squamous cell carcinoma in males and adenocarcinoma in females; diagnosis of NSCLC is made more frequently at the advanced stage but that of SCLC at limited stage; and the general increase in smoker population may lead to increased LC incidence in the Aegean region of Turkey. Thus, more effective efforts of education and campaigns for prevention and cessation of smoking must be implemented by the Turkish Health Ministry and other health organisations in Turkey, an attractive market for cigarette producers owing to its predominantly young population.

Acknowledgements: ITRHTMS Malignancy Study Group thanks Huseyin Halilcolar, Sena Yapicioglu and Semra Bilaceroglu for planning, analyzing data and writing the manuscript of this study that was carried out with the cooperation of the following investigators in data collection: Semra Bilaceroglu, Pinar Cimen, Kadri Cirak, Onur Erer, Salih Guçlu, Huseyin Halilcolar, Rifat Ozacar, Emel Ozden, Serir Ozkan, Ayse Ozsoz, Gulru Polat, Emel Tellioglu, Gultekin Tibet, Fevziye Tuksavul and Sena Yapicioglu.

\section{References}

1. Parkin GM, Pisani P, Ferlay J. Global cancer statistics. CA Cancer J Clin 1999; 49: 33-64.

2. Alberg AJ, Samet JM. Epidemiology of lung cancer. Chest 2003; 123: 21S-49S.

3. Nesbit JC, Lee JS, Komaki R, Roth JC. Cancer of the lung. In: Holand JF, Frei E, Bast RC, Kufe DW, Morton DL, Weichselbaum RR (eds.). Cancer Medicine. Williams \& Wilkins, Baltimore, 1997; 1723-805.

4. Turkish Health Ministry. Smoking habits and attitudes of Turkish population towards smoking and antismoking campaigns. PIAR, Ankara, 1988. (in Turkish)

5. Jemal A, Thomas A, Murray T, Thun M. Cancer statistics, 2002. CA Cancer J Clin 2002; 52: 23-47.

6. Jansen-Heijnen MLG, Coebergh JW. The changing epidemiology of lung cancer in Europe. Lung Cancer 2003; 41: 245-58.

7. Thun MJ, Lally CA, Flannery JT, et al. Cigarette smoking and changes in the histopathology of lung cancer. J Natl Cancer Inst 1997; 89: 1580-6.

8. Department of Cancer Control - Turkish Health Ministry. Cancer Registry Report of Turkey 1993-1994. Ministry of Health, Ankara, 1997. (in Turkish)

9. Fidaner C, Eser SY, Parkin DM. Incidence in Izmir in 1993-1994: first results from Izmir Cancer Registry. Eur J Cancer 2001; 37: 83-92.

10. World Health Organization. Histological Typing of Lung and Pleural Tumours. World Health Organization, Copenhagen, 1999.

11. Spiro SG, Silvestri GA. One hundred years of lung cancer. Am J Respir Crit Care Med 2005; 172: 523-9.

12. Postmus PE. Epidemiology of lung cancer. In: Fishman AP, Elias JA, Fishman JA, Grippi MA, Kaiser LR, Senior RM (eds.). Fishman's Pulmonary Diseases and Disorders. McGraw Hill, New York, 1998; 1707-19.

13. Gursel G, Levent E, Ozturk C, Karalezli A. Hospitalbased survey of lung cancer in Turkey, a developing country, where smoking is highly prevalent. Lung Cancer 1998; 21: 127-32.

14. Baldini EH, Strauss GM. Women and lung cancer: waiting to exhale. Chest 1997; 112: 229S-234S

15. Patel JD, Bach PB, Kris MG. Lung cancer in US women: a contemporary epidemic. JAMA 2004; 291: 1763-8.

16. Felip E, Novello S. Lung cancer in women. In: Postmus PE, Scagliotti GV, Kosmidis PA (ed.). 7th European Conference: Perspectives In Lung Cancer. Imedex, Inc., Athens, 2006; 95-9.

17. Spiro SG, Porter JC. Lung cancer - Where are we today? Current advances in staging and nonsurgical treatment. Am J Respir Crit Care Med 2002; 166: 1166-96.

18. Radzikowska E, Raszkowski K, Glaz P. Lung cancer in patients under 50 years old. Lung Cancer 2001; 33: 203-11.

19. Cancer Research UK, February 2003. Update 2006: Lung Cancer: UK Lung Cancer Incidence Statistics. http://info.cancerresearchuk.org/cancerstats/types/lung/ incidence/ Accessed: 7 August, 2007.

20. Goksel T, Akkoclu A. Turkish Thoracic Society, Lung and Pleural Malignancies Study Group. Pattern of lung cancer in Turkey, 1994-1998. Respiration 2002; 69: 207-10.

21. Itil O. Epidemiology and etiology of lung cancer. In: Haydaroglu A (ed.). Lung cancer: Diagnosis and treatment. Ege University, Izmir, 2000; 15-34. (in Turkish)

22. Dresler $\mathrm{C}$. The changing epidemiology of lung cancer. In: Postmus PE, Scagliotti GV, Kosmidis PA (ed.). 7th European Conference: Perspectives In Lung Cancer. Imedex, Inc., Athens, 2006; 9-17.

23. Tyczynski JE, Bray F, Parkin DM. Lung cancer in Europe in 2000: epidemiology, prevention, and early detection. Lancet Oncol 2003; 4: 45-55. 
24. Simonato L, Agudo A, Ahrens W, et al. Lung cancer and cigarette smoking in Europe: an update of risk estimates and an assesment of inter-country heterogeneity. Int J Cancer 2001; 91: 876-87.

25. Dosemeci M, Gokmen I, Unsal M, Hayes RB, Blair A. Tobacco, alcohol use, and risk of laryngeal and lung cancer by subsite and histologic type in Turkey. Cancer Causes Control 1997; 8: 729-37.

26. Travis WD, Lubin J, Ries L, Devesa S. United States lung carcinoma incidence trends. Cancer 1996; 77 : 2464-70.

27. Kubina M, Hedelin G, Charloux A, et al. Do patients with squamous cell carcinoma or adenocarcinoma of the lung have different smoking histories? Rev Mal Respir 1999; 16: 539-49

28. Skuladottir H, Olsen JH, Hirsch FR. Incidence of lung cancer in Denmark: historical and actual status. Lung Cancer 2000; 27: 107-18.

29. Lee CT, Kang KH, Koh Y, et al. Characteristics of lung cancer in Korea,1997. Lung Cancer 2000; 30: 15-22.
30. Peng D, Shen Y, Wang Z. Analysis on the surveillance materials of primary lung cancer from 1989 to 1994 in Shanghai. Respirology 1998; 3s: A38.

31. Hoffman PC, Mauer AM, Vokes EE. Lung cancer. Lancet 2000; 355: 479-85.

32. Charloux A, Quoix E, Wolkove N, et al. The increasing incidence of lung adenocarcinoma: reality or artefact? A review of the epidemiology of lung adenocarcinoma. Int J Epidemiol 1997; 26: 14-23.

33. Wynder EL, Hofmann D. Smoking and lung cancer: scientific chalenges and oppurtunities. Cancer Res 1994; 54: 5284-95.

34. Ettinger DS, Aisner J. Changing face of small cell lung cancer: Real and artifact. J Clin Oncol 2006; 28: 4526-7.

35. Rintoul RC, Sethi T. The lung cancer paradox: time for action. Thorax 2002; 57: 57-63.

36. Adjei AA, Marks RS, Bonner JA. Current guidelines fort he management of small cell lung cancer. Mayo Clin Proc 1999; 74: 809-16.

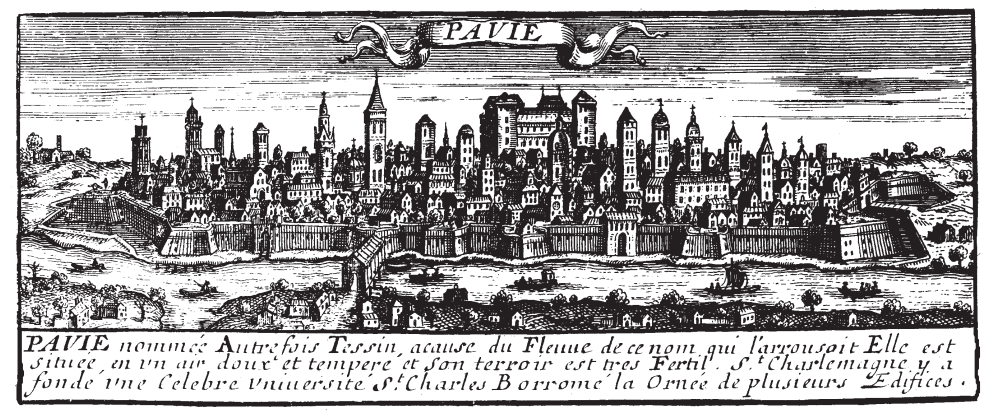

